\title{
Percutaneous balloon dilatation of the mitral valve: an analysis of echocardiographic variables related to outcome and the mechanism of dilatation
}

\author{
GERARD T WILKINS, ARTHUR E WEYMAN, VIVIAN M ABASCAL, \\ PETER C BLOCK, IGOR F PALACIOS
}

\section{From the Cardiac Unit, Department of Medicine, Massachusetts General Hospital, and Harvard Medical School, Boston, Massachusetts, USA}

SUMMARY Twenty two patients (four men, 18 women, mean age 56 years, range 21 to 88 years) with a history of rheumatic mitral stenosis were studied by cross sectional echocardiography before and after balloon dilatation of the mitral valve. The appearance of the mitral valve on the predilatation echocardiogram was scored for leaflet mobility, leaflet thickening, subvalvar thickening, and calcification. Mitral valve area, left atrial volume, transmitral pressure difference, pulmonary artery pressure, cardiac output, cardiac rhythm, New York Heart Association functional class, age, and sex were also studied. Because there was some increase in valve area in almost all patients the results were classified as optimal or suboptimal (final valve area $<1.0 \mathrm{~cm}^{2}$, final left atrial pressure $>10 \mathrm{~mm} \mathrm{Hg}$, or final valve area $<25 \%$ greater than the initial area). The best multiple logistic regression fit was found with the total echocardiographic score alone. A high score (advanced leaflet deformity) was associated with a suboptimal outcome while a low score (a mobile valve with limited thickening) was associated with an optimal outcome. No other haemodynamic or clinical variables emerged as predictors of outcome in this analysis. Examination of pre-dilatation and postdilatation echocardiograms showed that balloon dilatation reliably resulted in cleavage of the commissural plane and thus an increase in valve area.

Percutaneous balloon dilatation of the mitral valve is a promising new approach to the management of rheumatic mitral stenosis. ${ }^{1-9}$ But at this early stage little is known about the criteria for patient selection or the mechanism by which balloon dilatation increases mitral valve area. Previous experience with closed surgical commissurotomy suggests that mitral valve pliability and the degree of leaflet thickening have an important effect on subsequent outcome. ${ }^{10-15}$ Because cross sectional echocardiography shows the structure of the mitral apparatus, the severity of the stenotic lesion, and changes in chamber size ${ }^{1617}$ it should provide information that will predict the likely outcome of balloon dilatation.

\section{Patients and methods}

We studied the first 22 patients (four men and 18 women) who had percutaneous balloon dilatation

Requests for reprints to Dr Arthur E Weyman, Cardiac Noninvasive Laboratory, Phillips House 8, Massachusetts General Hospital, Fruit Street, Boston, MA 02114, USA.

Accepted for publication 24 February 1988 of the mitral valve at the Massachusetts General Hospital. They were aged from 21 to 88 years (mean 56.6). All patients had a diagnosis of rheumatic mitral stenosis on the basis of history and clinical examination.

To identify features that might predict the result of balloon dilatation we analysed 18 variables assessed at the clinical, echocardiographic, and haemodynamic examinations performed before the procedure. The clinical variables included cardiac rhythm, New York Heart Association functional class, age, and sex. From the echocardiogram we assessed structural features of the mitral valve and subvalvar apparatus, including the initial mitral valve area (by planimetry), initial left atrial size, and the pre-valvotomy grade of mitral regurgitation (by Doppler echocardiography). The haemodynamic features measured at catheterisation before balloon dilatation included mitral valve area, transmitral pressure difference, cardiac output, pulmonary vascular resistance, and left ventricular end diastolic pressure. The degree of mitral calcification was also assessed by radiology. 
Table 1 Individual clinical, haemodynamic, and echocardiographic results for the study group

\begin{tabular}{|c|c|c|c|c|c|c|c|c|c|c|c|c|c|c|c|c|}
\hline Patient & Age & Sex & Rhythm & $\begin{array}{l}\text { NYHA } \\
\text { class }\end{array}$ & $\begin{array}{l}\text { MVA-pre } \\
\text { Gorlin }\end{array}$ & $\begin{array}{l}\text { MVA-post } \\
\text { Gorlin }\end{array}$ & $\begin{array}{l}\text { Grad } \\
\text { pre }\end{array}$ & $\begin{array}{l}\text { Grad } \\
\text { post }\end{array}$ & $\begin{array}{l}\text { Pre } \\
L A-P\end{array}$ & $\begin{array}{l}\text { Post } \\
L A-P\end{array}$ & $\begin{array}{l}P A \\
\text { pre }\end{array}$ & $\begin{array}{l}P A \\
\text { post }\end{array}$ & Outcome & $\begin{array}{l}\text { Total } \\
\text { score }\end{array}$ & $\begin{array}{l}M V A- \\
\text { pre } \\
\text { echo }\end{array}$ & $\begin{array}{l}M V A \\
\text { post } \\
\text { echo }\end{array}$ \\
\hline $\begin{array}{r}1 \\
2 \\
3 \\
4 \\
5 \\
6 \\
7 \\
8 \\
9 \\
10 \\
11 \\
12 \\
13 \\
14 \\
15 \\
16 \\
17 \\
18 \\
19 \\
20 \\
21 \\
22\end{array}$ & $\begin{array}{l}67 \\
71 \\
72 \\
57 \\
56 \\
49 \\
40 \\
42 \\
59 \\
40 \\
88 \\
27 \\
71 \\
47 \\
68 \\
64 \\
72 \\
21 \\
78 \\
51 \\
53 \\
54\end{array}$ & $\begin{array}{l}\mathbf{M} \\
\mathbf{M} \\
\mathbf{F} \\
\mathbf{F} \\
\mathbf{F} \\
\mathbf{F} \\
\mathbf{F} \\
\mathbf{F} \\
\mathbf{F} \\
\mathbf{F} \\
\mathbf{F} \\
\mathbf{F} \\
\mathbf{F} \\
\mathbf{F} \\
\mathbf{F} \\
\mathbf{F} \\
\mathbf{F} \\
\mathbf{M} \\
\mathbf{F} \\
\mathbf{M} \\
\mathbf{F} \\
\mathbf{F}\end{array}$ & $\begin{array}{l}\text { SR } \\
\text { AF } \\
\text { AF } \\
\text { SR } \\
\text { SR } \\
\text { AF } \\
\text { SR } \\
\text { SR } \\
\text { SR } \\
\text { SR } \\
\text { AF } \\
\text { SR } \\
\text { AF } \\
\text { SR } \\
\text { AF } \\
\text { AF } \\
\text { SR } \\
\text { SR } \\
\text { AF } \\
\text { SR } \\
\text { AF } \\
\text { SR }\end{array}$ & $\begin{array}{l}\text { IV } \\
\text { III } \\
\text { III } \\
\text { III } \\
\text { III } \\
\text { III } \\
\text { II } \\
\text { III } \\
\text { IV } \\
\text { III } \\
\text { IV } \\
\text { III } \\
\text { IV } \\
\text { III } \\
\text { IV } \\
\text { III } \\
\text { IV } \\
\text { III } \\
\text { IV } \\
\text { III } \\
\text { III } \\
\text { IV }\end{array}$ & $\begin{array}{l}0.7 \\
0.7 \\
0.9 \\
1.6 \\
1.0 \\
0.8 \\
0.7 \\
1.1 \\
0.4 \\
1.0 \\
0.5 \\
0.7 \\
0.5 \\
0.8 \\
0.7 \\
0.6 \\
0.9 \\
0.6 \\
0.4 \\
0.6 \\
1.4 \\
0.5\end{array}$ & $\begin{array}{l}2.5 \\
1.5 \\
1.7 \\
2.9 \\
2.2 \\
1.5 \\
2.0 \\
1.3 \\
1.6 \\
2.3 \\
1.0 \\
2.8 \\
1.2 \\
2.1 \\
0.8 \\
1.5 \\
1.7 \\
1.8 \\
\ddagger \\
2.1 \\
1.6 \\
0.9\end{array}$ & $\begin{array}{r}20 \\
12 \\
9 \\
15 \\
18 \\
9 \\
30 \\
28 \\
22 \\
25 \\
15 \\
24 \\
18 \\
20 \\
9 \\
12 \\
17 \\
15 \\
20 \\
25 \\
16 \\
31\end{array}$ & $\begin{array}{r}4 \\
8 \\
5 \\
6 \\
5 \\
5 \\
6 \\
14 \\
2 \\
5 \\
4 \\
4 \\
5 \\
7 \\
8 \\
5 \\
4 \\
3 \\
\ddagger \\
5 \\
12 \\
11\end{array}$ & $\begin{array}{l}42 \\
22 \\
15 \\
15 \\
25 \\
17 \\
38 \\
32 \\
20 \\
30 \\
35 \\
30 \\
22 \\
32 \\
20 \\
18 \\
21 \\
22 \\
35 \\
25 \\
21 \\
39\end{array}$ & $\begin{array}{r}25 \\
19 \\
10 \\
10 \\
5 \\
18 \\
10 \\
18 \\
10 \\
7 \\
20 \\
8 \\
17 \\
10 \\
12 \\
10 \\
22 \\
6 \\
\ddagger \\
5 \\
12 \\
12\end{array}$ & $\begin{array}{l}50 \\
52 \\
21 \\
25 \\
34 \\
31 \\
75 \\
40 \\
48 \\
40 \\
52 \\
42 \\
53 \\
40 \\
50 \\
45 \\
30 \\
35 \\
40 \\
36 \\
32 \\
62\end{array}$ & $\begin{array}{l}40 \\
38 \\
18 \\
20 \\
14 \\
35 \\
35 \\
25 \\
15 \\
25 \\
35 \\
18 \\
40 \\
28 \\
40 \\
35 \\
+ \\
20 \\
\ddagger \\
25 \\
17 \\
29\end{array}$ & $\begin{array}{l}\text { Sub } \\
\text { Sub } \\
\text { Opt } \\
\text { Opt } \\
\text { Opt } \\
\text { Sub } \\
\text { Opt } \\
\text { Sub } \\
\text { Opt } \\
\text { Opt } \\
\text { Sub } \\
\text { Opt } \\
\text { Sub } \\
\text { Opt } \\
\text { Sub } \\
\text { Opt } \\
\text { Sub } \\
\text { Opt } \\
\text { Sub } \\
\text { Opt } \\
\text { Sub } \\
\text { Sub }\end{array}$ & $\begin{array}{r}14 \\
10 \\
6 \\
9 \\
7 \\
9 \\
5 \\
9 \\
11 \\
5 \\
14 \\
7 \\
16 \\
5 \\
10 \\
11 \\
10 \\
4 \\
12 \\
10 \\
11 \\
11\end{array}$ & $\begin{array}{l}0.5 \\
1.2 \\
1.8 \\
1.4 \\
0.9 \\
1.0 \\
1.0 \\
1.0 \\
0.4 \\
0.8 \\
0.8 \\
0.7 \\
+ \\
1.1 \\
0.8 \\
0.8 \\
0.9 \\
0.6 \\
0.4 \\
0.5 \\
1.4 \\
1.1\end{array}$ & $\begin{array}{l}1.8 \\
\dagger \\
2.4 \\
2.0 \\
1.6 \\
1.5 \\
2.1 \\
1.5 \\
1.4 \\
2.0 \\
1.6 \\
2.4 \\
\dagger \\
2.1 \\
0.8 \\
1.1 \\
1.7 \\
1.8 \\
\ddagger \\
2.3 \\
1.6 \\
1.2\end{array}$ \\
\hline
\end{tabular}

SR, sinus rhythm; AF, atrial fibrillation; NYHA, New York Heart Association functional class; MVA-pre and MVA-post, Gorlin mitral valve area before and after balloon dilatation; Grad pre and Grad post, mean transmitral gradient before and after balloon dilatation; Pre LA-P and post LA-P, mean left at \& pressure before and after balloon dilatation; PA pre and PA post, mean pulmonary artery pressure before and after balloon dilatation; MVA-pre and MVApost, echocardiographic mitral valve area before and after balloon dilatation; ${ }^{\star}$ total echocardiographic score; †Technically limited measuremeuts; $\ddagger$ Measurements not performed because of acute haemodynamic deterioration.

CLINICAL FEATURES

Of the 22 patients, 13 were in sinus rhythm and 9 were in atrial fibrillation. By the New York Heart Association functional class, one (5\%) patient was in class II, $13(59 \%)$ were in class III, and $8(36 \%)$ were in class IV.

\section{ECHOCARDIOGRAPHIC FEATURES}

Each patient was studied by cross sectional and Doppler echocardiography before the procedure. Most studies ( 20 of $22,91 \%$ ) were performed within 24 hours of the procedure; the remaining two studies were performed within three months. To analyse the effect of mitral valve structure on the results of dilatation, we scored the echocardiographic study of each patient for: $(a)$ leaflet mobility, $(b)$ leaflet thickening, (c) subvalvar thickening, and (d) calcification. Table 2 shows the scoring system. We gave each of the above features a score of $0-4$, and higher scores represented more abnormal structure. For example, for mobility, grade 1 was a highly mobile valve with restriction of only the leaflet tips. Grade 4 indicated a valve that was almost completely immobile with no (or minimal) forward movement

Table 2 Grading of mitral valve characteristics from the echocardiographic examination

\begin{tabular}{|c|c|c|c|c|}
\hline Grade & Mobility & Subvalvar thickening & Thickening & Calcification \\
\hline 1 & $\begin{array}{l}\text { Highly mobile valve with only } \\
\text { leaflet tips restricted }\end{array}$ & $\begin{array}{l}\text { Minimal thickening just } \\
\text { below the mitral leaflets }\end{array}$ & $\begin{array}{l}\text { Leaflets near normal in } \\
\text { thickness }(4-5 \mathrm{~mm})\end{array}$ & $\begin{array}{l}\text { A single area of increased } \\
\text { echo brightness }\end{array}$ \\
\hline 2 & $\begin{array}{l}\text { Leaflet mid and base portions } \\
\text { have normal mobility }\end{array}$ & $\begin{array}{l}\text { Thickening of chordal } \\
\text { structures extending up to } \\
\text { one third of the } \\
\text { chordal length }\end{array}$ & $\begin{array}{l}\text { Mid-leaflets normal, } \\
\text { considerable thickening of } \\
\text { margins }(5-8 \mathrm{~mm})\end{array}$ & $\begin{array}{l}\text { Scattered areas of brightness } \\
\text { confined to leaflet margins }\end{array}$ \\
\hline 3 & $\begin{array}{l}\text { Valve continues to move } \\
\text { forward in diastole, } \\
\text { mainly from the base }\end{array}$ & $\begin{array}{l}\text { Thickening extending to the } \\
\text { distal third of the } \\
\text { chords }\end{array}$ & $\begin{array}{l}\text { Thickening extending } \\
\text { through the entire leaflet } \\
(5-8 \mathrm{~mm})\end{array}$ & $\begin{array}{l}\text { Brightness extending into the } \\
\text { mid-portion of the } \\
\text { leaflets }\end{array}$ \\
\hline 4 & $\begin{array}{l}\text { No or minimal forward } \\
\text { movement of the leaflets } \\
\text { in diastole }\end{array}$ & $\begin{array}{l}\text { Extensive thickening and } \\
\text { shortening of all chordal } \\
\text { structures extending down } \\
\text { to the papillary muscles }\end{array}$ & $\begin{array}{l}\text { Considerable thickening of all } \\
\text { leaflet tissue }(>8-10 \mathrm{~mm})\end{array}$ & $\begin{array}{l}\text { Extensive brightness } \\
\text { throughout much of } \\
\text { the leaflet tissue }\end{array}$ \\
\hline
\end{tabular}

The total echocardiographic score was derived from an analysis of mitral leaflet mobility, valvar and subvalvar thickening, and calcification which were graded from 0 to 4 according to the above criteria. This gave a total score of 0 to 16 . 

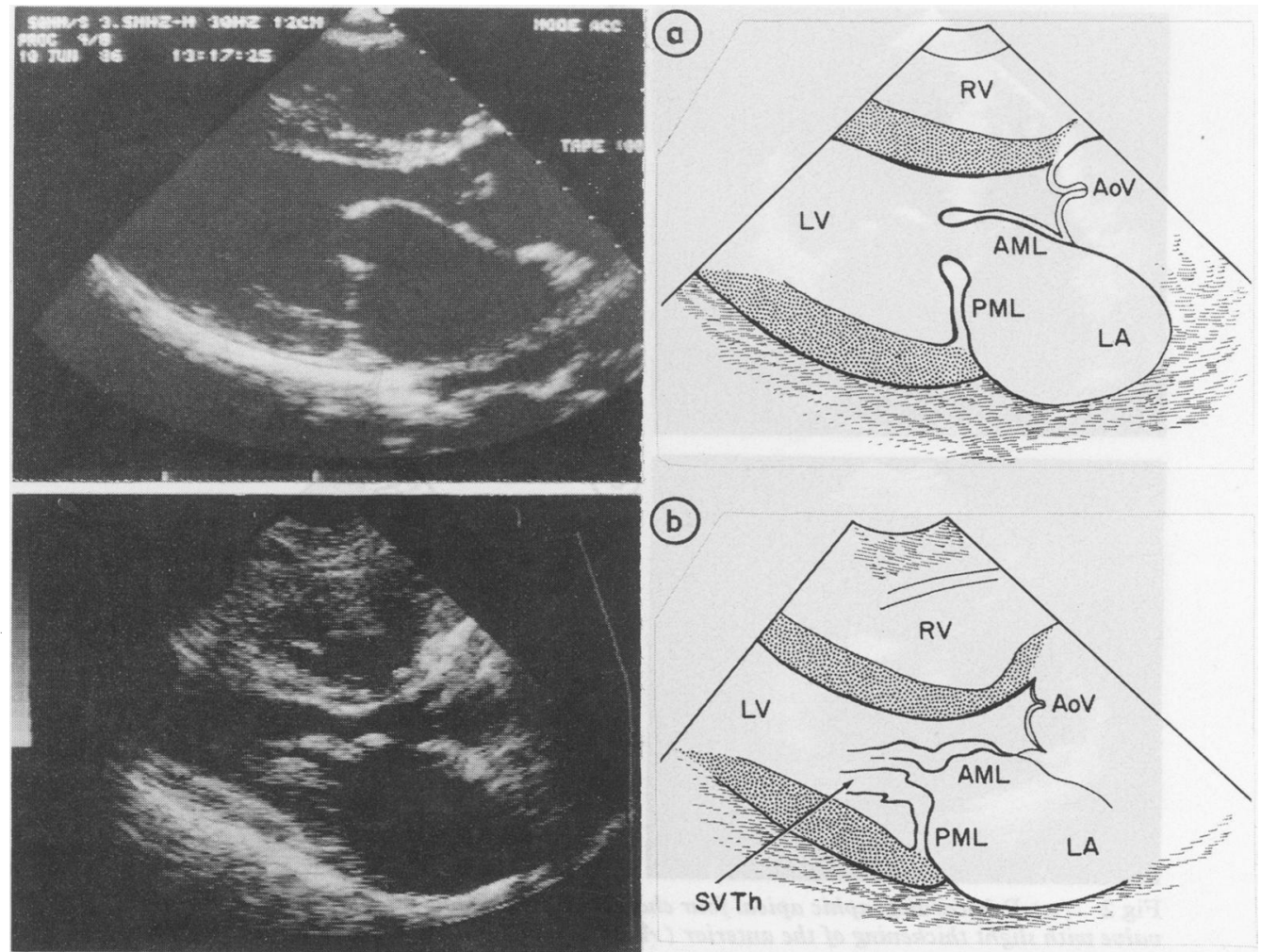

Fig 1 (a) Echocardiographic parasternal long axis view showing a highly mobile, "doming" anterior (AML) and posterior (PML) mitral valve with slightly thickened leaflet tips. There is no evidence of subvalvar thickening. The echo score is 4. (b) The mitral leaflets are thickened and this thickening (SVTh) extends below the leaflet tips into the subvalvar apparatus. The echo score is 11.

during diastole (figs 1 and 2). Summing the individual scores resulted in a total echocardiographic score. According to this system, a score of 0 would be a totally normal valve (no such valve was included in this series), while a score of 16 would represent an immobile valve with considerable thickening of the leaflets and subvalvar apparatus and severe superimposed calcification.

Subvalvar thickening was best displayed by a series of modified views. In the parasternal long axis view, the standard aligned view was tilted medially and laterally so that the long axis of each papillary muscle and its attached chordal apparatus could be examined in turn. From the apical window, the extent of subvalvar shortening and scar was best viewed in a four chamber view with the transducer angled more posteriorly into the left ventricle, or from a foreshortened two chamber view angled medially and laterally.

The left atrial volume was calculated from the echocardiographic images before and after the procedure by an ellipsoid formula, in which the length was taken as the superior-inferior length of the atrium in the apical four chamber view and the two diameters used were the anterior-posterior and medial-lateral dimensions measured in the parasternal long and short axis views respectively (fig 3 ). The anterior-posterior diameter (D1, fig 3a) and the superior-inferior length (D3, fig 3c) were measured in the frame obtained immediately before mitral valve opening. The medial-lateral diameter (D2, fig 3b) was measured in a view in which the mitral valve cannot be seen in the frame during which aortic valve closure was completed. Mitral valve area was measured by direct planimetry in the standard manner ${ }^{1617}$ before and within 24 hours of the procedure (fig 4). Technically satisfactory images of the mitral valve orifice suitable for planimetry could not be obtained either before or after the procedure in one patient and after the procedure in another (patients 13 and 2 respectively, table 1). The presence and extent of mitral regurgitation were also mapped 

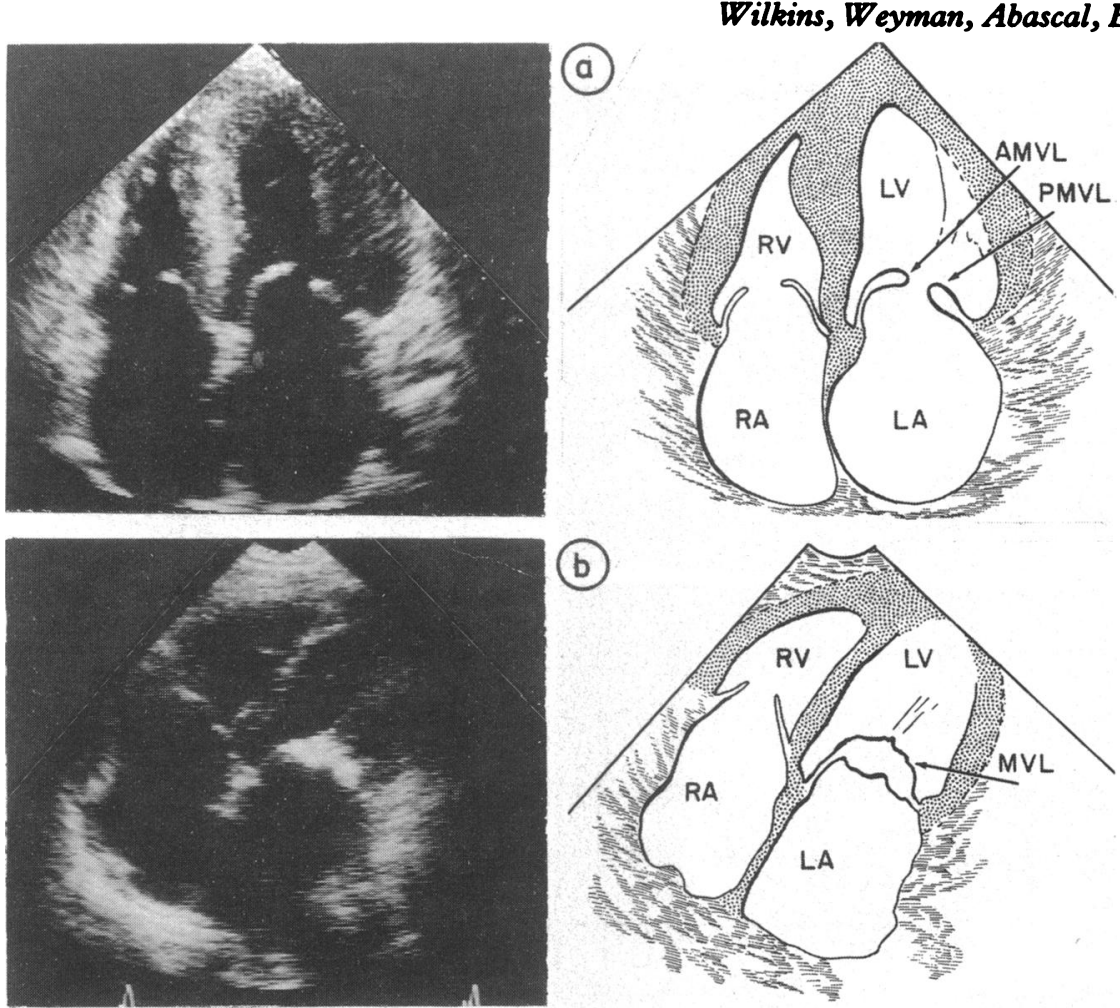

Fig 2 (a) Echocardiographic apical four chamber view showing "doming" of the mitral valve with slight thickening of the anterior ( $A M V L$ ) and posterior (PMVL) leaflet tips. The echo score is 4. (b) Extensive thickening of the leaflets (MVL) and a considerable increase in echo density suggesting the presence of calcification. The echo score is 14.

before and after the procedure by the pulsed Doppler technique in order to assess any adverse effect of this variable on outcome. ${ }^{18}$ Mitral regurgitation was graded on a scale of 1 to $4+$ by dividing the atrium into four equal segments along its long axis and constructing an arc centred at the mid-point of the mitral valve that extended from the end of each quadrisecting point to the medial and lateral walls of the atrium. High velocity systolic flow was then graded according to its penetration into these segments. Grade 4 represented flow detected at the rast superior atrial segment.

\section{HAEMODYNAMIC VARIABLES}

Each patient was catheterised from the right femoral approach. The interatrial septum was first crossed by the Brockenborough technique. A flow directed catheter was then passed through the transseptal sheath and, together with a flexible exchange guide wire, advanced through the mitral valve orifice. Left atrial and left ventricular pressures were measured, and the mean transmitral pressure difference was calculated. Pulmonary artery pressure was measured with a Swan-Ganz catheter inserted via the internal jugular vein. Cardiac output was measured by thermodilution, Fick, or green dye dilution techniques? We calculated the mitral valve area by the Gorlin equation. ${ }^{19}$

After these haemodynamic measurements, per-? cutaneous balloon dilatation of the mitral valve was 3 . performed by either a single or double balloon dilating technique. ${ }^{7}$ A single balloon procedure was performed in 17 patients: a single $15 \mathrm{~mm}$ balloon in one, a single $20 \mathrm{~mm}$ balloon in one, and a single $25 \mathrm{~mm}$ balloon in 15 patients. In four patients double balloon procedure was performed with a combination of a $25 \mathrm{~mm}$ and $15 \mathrm{~mm}$ balloon. Onces the catheter(s) was positioned across the orifice, the balloon(s) was inflated by hand until the indentation caused by the stenotic mitral valve disappeared. Each inflation lasted approximately 15 seconds and multiple inflations were performed in all patients. In one patient (patient 19, table 1) the valve could not be crossed with an $8 \mathrm{~mm}$ balloon catheter, and the patient became profoundly hypotensive. Mitral valve replacement was uneventful, but the patient could not be weaned from cardiopulmonary bypass becaus $\tilde{D}_{2}$ of profound right heart failure and she died. 

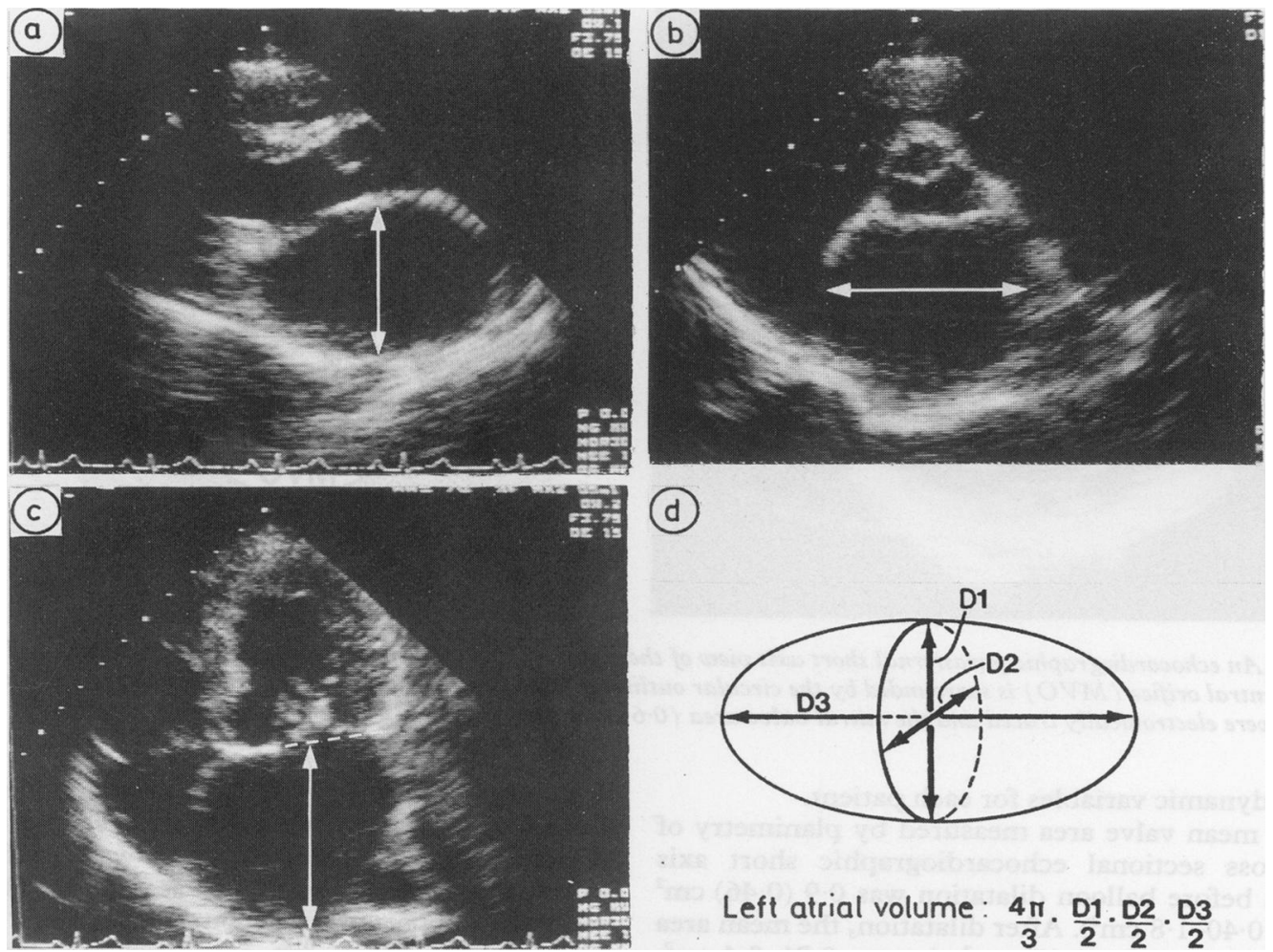

Fig 3 The derivation of the orthogonal diameters from which the left atrial volume was calculated. (a) The anterior-posterior diameter from the parasternal long axis view. (b) The medial-lateral diameter from the parasternal short axis view. (c) The superior-inferior diameter from the apical four-chamber view. These diameters were used to calculate the left atrial volume from an ellipsoid-biplane formula (d).

\section{FLUOROSCOPIC CALCIFICATION}

The grade of mitral calcification was assessed by the fluoroscopic examination conducted at catheterisation. The grade was qualitatively scored from 0 (no calcification seen) to 4 (severe calcification).

\section{STATISTICAL ANALYSIS}

To determine whether any variable or combination of variables predicted a successful outcome of balloon dilatation, all echocardiographic, Doppler, haemodynamic, and clinical data were analysed by multiple logistic regression analysis. The dependent variable was either an optimal or a suboptimal result. A suboptimal result was defined as any one or more of the following: (a) a final valve area $\leqslant 1.0 \mathrm{~cm}^{2},(b)$ a post-dilatation mean left atrial pressure $>10 \mathrm{~mm}$ $\mathrm{Hg}$, or (c) a change in area $<25 \%$ of the initial valve area in those with a mitral valve area $>1.0 \mathrm{~cm}^{2}$ before the procedure.

One patient (case 19, table 1) who died soon after attempted percutaneous mitral balloon dilatation was included in the analysis on the basis of intention to treat.

Multiple logistic regression analysis was performed in the standard manner with a commercial statistical package, BMDP. ${ }^{20}$ Data are presented as mean (1 SD). The outcome in the subgroups (optimal $v$ suboptimal) was compared by the unpaired Student's $t$ test for parametric data or the Wilcoxon signed rank test for non-parametric data. The frequency of events was compared by the $\chi^{2}$ or Fisher's exact test. Interobserver variability was determined from the mean unsigned differences between two sets of measurements performed blindly by two experienced observers. Intraobserver variability was determined in the same way from two sets of measurements performed by the same observer on different days.

\section{Results}

Table 1 shows the clinical, echocardiographic, and 

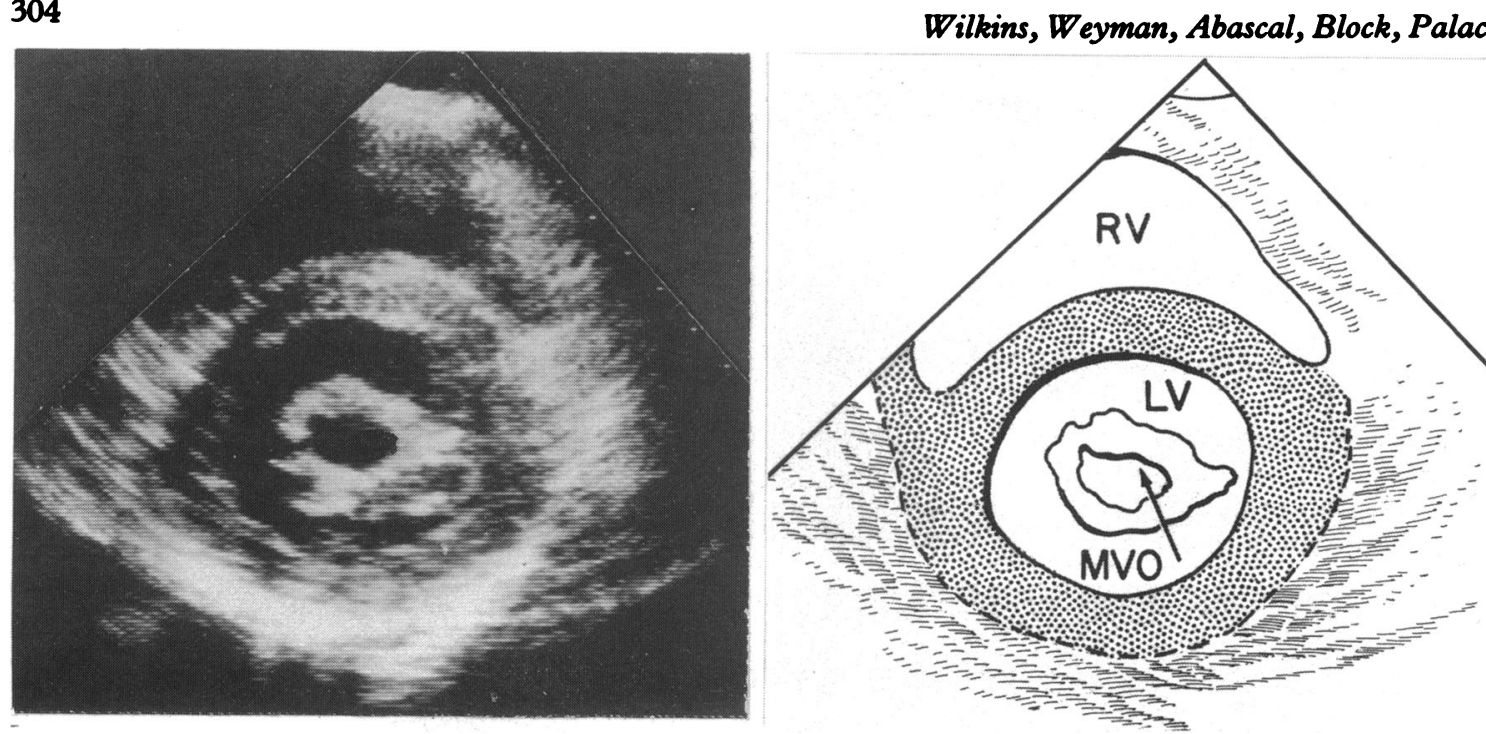

Fig 4 An echocardiographic parasternal short axis view of the mitral valve orifice in diastole (patient 16, table 1). The small central orifice (MVO) is surrounded by the circular outline of the left ventricular cavity. The margins of the central orifice were electronically traced and the mitral valve area $\left(0.6 \mathrm{~cm}^{2}\right)$ was calculated by planimetry.

haemodynamic variables for each patient.

The mean valve area measured by planimetry of the cross sectional echocardiographic short axis images before balloon dilatation was $0.9(0.46) \mathrm{cm}^{2}$ (range $0.40-1.8 \mathrm{~cm}^{2}$ ). After dilatation, the mean area increased to $1.7(0.45) \mathrm{cm}^{2}$ (range $0.81-2.4 \mathrm{~cm}^{2}$, $\mathrm{p}<0.0001$ ). The individual increases in valve area varied considerably, and ranged from 0.1 to $1.81 \mathrm{~cm}^{2}$.

The mean valve area measured by the catheterisation method (Gorlin equation) before balloon dilatation was $0.8(0.30) \mathrm{cm}^{2}$ (range $0.4-1.6 \mathrm{~cm}^{2}$ ). After balloon dilatation, the mean area increased to $1.76(0.6) \mathrm{cm}^{2}$ (range $0.8-2.9 \mathrm{~cm}^{2}, \mathrm{p}<0.0001$ ). Changes in valve area measured by the planimetry method and by the Gorlin equation were strongly correlated $(r=0.9, p<0.001)$.

Table 1 shows total echocardiographic score for leaflet mobility, leaflet thickening, leaflet calcification, and subvalvar thickening for each patient before balloon dilatation. On a scale of 0 to 16 , representing increasing structural deformity, the severity ranged widely from 4 to 16 (mean grade 9.4 (3.1)). In 12 randomly selected cases, the mean interobserver variability for the total echocardiographic score was $0.41(0.51)$. The intraobserver variability for the echocardiographic score in the same patients was $0.38(0.4)$.

The mean grade of regurgitation by Doppler was $1.0(1.2)$ with a range of 0 to 3 . After dilatation, the mean grade of regurgitation increased to $1.8(1 \cdot 1)$ and ranged from 0 to 3 . Although this increase in the degree of regurgitation (by Doppler) represented a significant increase ( $\mathbf{p}<0.01$ ), no patient developed ${ }^{\circ}$ grade 4 regurgitation. Mean left atrial volume was 950 (47) $\mathrm{cm}^{3}$ (range $52-220 \mathrm{~cm}^{3}$ ), which was significantly larger than the normal values of $32(10) \mathrm{cm}^{3}$ 음 previously reported from our laboratory. ${ }^{21}$ Aftero dilatation the mean left atrial volume decrease $D_{B}$ significantly to $83(12) \mathrm{cm}^{3}(p<0.001)$.

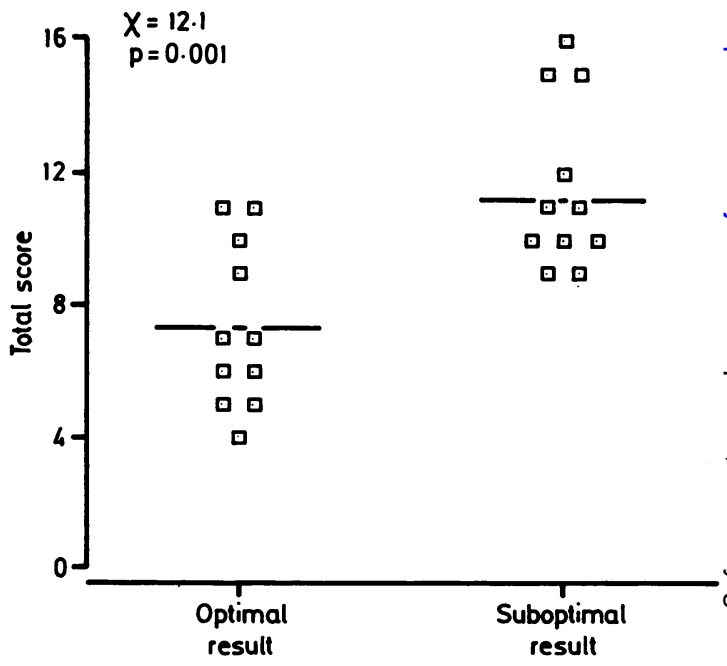

Fig 5 Total echocardiographic score for each patient (from 0 to 16) in patients grouped according to outcome. The bar shows mean total score for each group. Logistic regression analysis according to outcome selected the total echocardiographic score alone as the best predictor. 

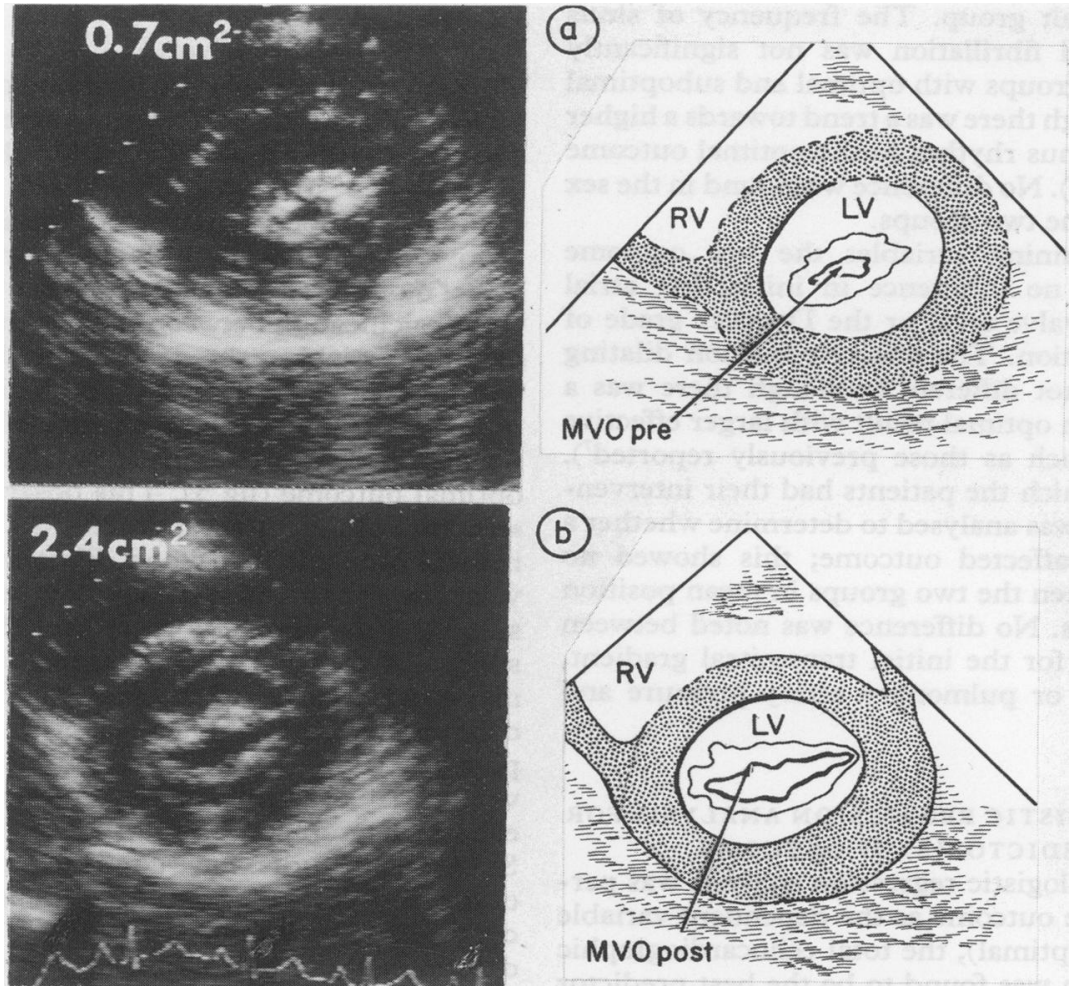

Fig 6 Cross sectional echocardiographic images from study patient 12 (table 1) immediately before and 24 hours after balloon dilatation of the mitral valve. (a) The small central orifice $\left(0.7 \mathrm{~cm}^{2}\right)$ (MVO pre). After the procedure, the orifice (MVO post) was significantly larger $\left(2.4 \mathrm{~cm}^{2}\right)$ (b) with cleavage along the medial and lateral commissures which had previously appeared as dense scarred regions.

The mean grade of calcification (by fluoroscopy) was $1.4(1.5)$ and ranged from grade 0 to 4 . Ten patients had no obvious calcification of the leaflets by fluoroscopic examination and only one had grade 4 calcification.

The haemodynamic data showed a mean transmitral pressure difference of $18.6(6.6) \mathrm{mm} \mathrm{Hg}$, mean cardiac output of $3.9(1.21 / \mathrm{min})$, mean pulmonary vascular resistance of 384 (289) dynes.s. $\mathrm{cm}^{-5}$, and a mean left ventricular end diastolic pressure of 8 (3) $\mathrm{mm} \mathbf{~ H g}$.

The mean dilating area of the balloon(s) was $4.89 \mathrm{~cm}^{2}$ (approximately equal to a single 25 French balloon).

\section{ANALYSIS FOR PREDICTORS OF AN OPTIMAL OR SUBOPTIMAL RESULT}

There were 11 patients with an optimal result and 11 patients with a suboptimal result (see Methods section for criteria).

Comparison of the mitral valve structure in the groups with optimal and suboptimal outcome showed significant differences in the degrees of valve mobility (mean optimal group $1.8(0.96)$ and mean suboptimal group $3.18(0.75), p<0.001)$, valve thickening (mean optimal group $2 \cdot 1(0 \cdot 8)$ and mean suboptimal group $3.2(0.6), p<0.001)$, subvalvar thickening (mean optimal group $1.7(0.6)$ and mean suboptimal group $2.5(0.8), p<0.01)$, and valve calcification (mean optimal group $1.8(0.9)$ and mean suboptimal group $2.6(0.8) \mathrm{p}<0.03)$. The total echocardiographic score was also significantly different in the two groups (mean optimal group 7.36 (2.5) (range 4-11) and suboptimal group $11.5(2.3)$ (range 9-16), p $<0.001$ ), with an optimal outcome associated with a lower score (fig 5).

Analysis of the clinical variables showed that the mean New York Heart Association functional class was lower (optimal 3.0 (0.4) and suboptimal 3.63 $(0.5), p=0.005)$ and the mean fluoroscopic grade of calcification was lower (mean optimal grade 0.5(1.0) and mean suboptimal grade $2.3(1.4), p=0.003)$ in 
the optimal result group. The frequency of sinus rhythm or atrial fibrillation was not significantly different in the groups with optimal and suboptimal outcome, although there was a trend towards a higher occurrence of sinus rhythm in the optimal outcome group $(p=0.08)$. No difference was found in the sex distribution of the two groups.

For the remaining variables the two outcome groups showed no difference in initial left atrial volume, initial valve area, or the Doppler grade of mitral regurgitation. The effective balloon dilating area used was not different (although there was a trend towards an optimal result with larger effective balloon areas such as those previously reported ${ }^{7}$ ). The order in which the patients had their intervention performed was analysed to determine whether a learning curve affected outcome; this showed no difference between the two groups in mean position within the series. No difference was noted between the two groups for the initial transmitral gradient, cardiac output, or pulmonary artery pressure and resistance.

MULTIPLE LOGISTIC REGRESSION ANALYSIS FOR THE MAJOR PREDICTOR(S) OF OUTCOME

When multiple logistic regression analysis was performed with the outcome as the dependent variable (optimal $v$ suboptimal), the total echocardiographic score on its own was found to be the best predictor (multiple $\chi^{2}=12.1, p<0.0001$ ). The fit of the logistic regression was not improved by the addition of any other variable. Figure 5 shows the individual total echocardiographic scores for each patient and the outcome group to which each individual belongs. Although four patients with relatively high scores (that is significant immobility, thickening, and subvalvar thickening) had an optimal result. In general, however, the analysis suggested that a high score was associated with a suboptimal outcome.

ANALYSIS FOR THE MECHANISM OF DILATATION Careful examination of the short axis echocardiographic images showed that successful balloon dilatation of the mitral valve was associated with cleavage along the commissures (fig 6). This appearance occurred even in those patients who had significantly thickened and calcified valve leaflets, although the degree of cleavage was less. Balloon dilatation in some patients with high total echocardiographic scores seemed to produce extensive commissural splitting, but, despite this, the separation of the leaflets in diastole remained poor. So the orifice area failed to increase relative to the increase in circumference, presumably because the deformed leaflets were unable to assume a more circular shape.

\section{Discussion}

This study shows that the outcome of percutaneous balloon dilatation of the mitral valve is most closet associated with echocardiographic characteristics of mitral valve structure. The mean values for the optimal and suboptimal outcome groups showed that there were significant differences in the degree of leaflet mobility, valvar and subvalvar thickening, and valve calcification between the two groups. For eact of these variables, the greater the degree of leaflet deformity, the greater was the likelihood of a sub optimal outcome, and, conversely, valves with a more normal structure tended to be associated with aio optimal outcome (fig 5). This observation, that the structure of the mitral apparatus is a major determirnant of outcome in balloon dilatation of the mitra valve, is consistent with previous experience with surgical valvotomy. As early as 1953, Sellors et at suggested that the type of mitral stenosis was the major determinant of the success of closed surgica commissurotomy. ${ }^{11}$ Their careful analysis of the physical signs related to a "pliant diaphragmatic valve" is the clinical forerunner of our owes echocardiographic observations on leaflet mobility. Subsequent studies have confirmed that the mobilit of the valve leaflets determined at operation ${ }^{12}$ and the degree of fibrosis and calcification, ${ }^{13-15}$ are the major determinants of both the short term and long terma results of closed mitral commissurotomy. Indeed, the poor results obtained in those patients with evidence of advanced valvar and subvalvar disease have led to the common practice of open mitrat commissurotomy on cardiopulmonary bypass, when the leaflets can be more directly inspected and incised. ${ }^{13}$

Although the primary structural feature that determines the haemodynamic severity of mitra stenosis is the mitral valve orifice area, the size of thie orifice was in no way predictive of the outcome. Patients with small initial valve areas over the range studied were just as likely to have an optimal result as those with larger valve areas before the procedure. This finding is somewhat surprising since we wouत have expected the valve with the smallest areas to have the most associated deformity and thus a poor result. This finding may relate to the highly selectegd patient group, since only those with critical disease were initially felt to be suitable for this new procedure. Since most valve areas were in the range of $0.4-1.0 \mathrm{~cm}^{2}$ it might be difficult reliably to separape out the effects of initial valve area upon the outcom This consideration is important, however, becaus our results suggest that this procedure may applied to patients with less severe mitral stenosps (larger valve areas) and at an earlier stage in the 
natural history of their disease, when the leaflets are less thickened and more mobile. As this group increases, valve area may also prove to be a predictor of outcome.

Several clinical factors, other than the echocardiographic variables, were also related to an optimal outcome. These factors were the presence of a lower New York Heart Association functional class, and a lower fluoroscopic grade of calcification. The initial haemodynamic variables that we measured (pre-dilatation transmitral gradient, cardiac output, and pulmonary artery pressure and resistance) were not related to immediate outcome in this group of patients. These findings are also consistent with previous surgical results after commissurotomy. ${ }^{12-15}$

A simple comparison of mean values in our study shows that both echocardiographic and clinical factors distinguished between the optimal and suboptimal outcome groups. Since this analysis does not determine the most important variable or combination of variables that may predict outcome, a multiple logistic regression analysis was performed to weigh the significance of each of these factors. This approach showed the single most important factor that could be related to outcome was the total echocardiographic score, which expressed the combined assessment of leaflet mobility, valvar and subvalvar thickening, and leaflet calcification. With this score we were able to assess differing degrees of leaflet immobility, deformity, and scarring. All patients with a total echocardiographic score $>11$ had a suboptimal result while all those with a score $<9$ had an optimal result. The score failed to predict outcome in those with scores of 9 to 11 (fig 5). Of the echocardiographic variables, no single factor, such as subvalvar thickening or valvar mobility alone, could be separated from the other structural features as a significant determinant of outcome. The addition of haemodynamic or clinical variables or both, individually or in combination, also failed to improve the logistic fit. Thus although outcome in this group of patients is associated both with echocardiographic and clinical variables it is best predicted by the echocardiographic score alone.

The effective dilating area of the balloon was not a significant predictor of outcome. Clearly, a much greater dilating area can be achieved with the use of a double balloon technique, such as that described by Al Zaibag et $a l^{4}$ and Palacios et al. ${ }^{7}$ This series, representing our earlier experience, contains only four patients in whom we used a double balloon technique. Nevertheless, we saw a trend towards a better result. We therefore believe that the effective dilating area of the balloon would have emerged as a significant determinant of outcome ${ }^{7}$ had more patients with a double balloon procedure been included in the analysis.

Finally, balloon dilatation of the mitral valve seemed reliably to result in splitting of the mitral commissures and not in traumatic avulsion or damage to the leaflet bodies. Since the inflation of a fluid-filled balloon within the confines of a small orifice results in equal pressure being applied to all points on the surface, separation of the valve along the plane of least resistance (that is the commissures) is to be expected (fig 6).

\section{LIMITATIONS OF THE STUDY}

The echocardiographic analysis presented in this report is based on a qualitative assessment of the mitral valve and apparatus. Although a more objective method of assessment may be desirable, it should be remembered that when surgeons or pathologists are able to handle the mitral valve they still describe any structural deformities in a qualitative manner because there are no accepted objective measures of mobility, thickening, or subvalvar thickening. Indeed it could be argued that because cross sectional echocardiography provides an assessment of these features (particularly mobility) in the beating heart it is better than examination during cardiopulmonary bypass or at necropsy. The simplicity of the approach that we have described should make it a practical clinical method of assessing patients before balloon dilatation of the mitral valve.

With a qualitative method there may be differences between observers in the assessment of the degree of mitral mobility, valvar and subvalvar thickening, and valve calcification. None the less, the interobserver and intraobserver variability for experienced observers was acceptably low. The accuracy of the assessment of structure also depends on the quality of the echocardiographic images obtained. The pathophysiology of mitral stenosis, with secondary right ventricular and biatrial enlargement, facilitates echocardiographic imaging and visualisation of the mitral valve. Moreover, none of the patients in our series was excluded because we could not adequately assess mitral valve structure by echocardiography.

\section{CONCLUSION}

This study shows that the outcome of percutaneous balloon dilatation of the mitral valve is related to the structure of the mitral valve and the subvalvar apparatus. Simple criteria obtained non-invasively can predict the likelihood of success of the procedure and hence may be used to select suitable patients. Since the most favourable early results were seen in patients with the least advanced valve deformity and scarring, this study implies that the procedure is most successful in this group and should be perfor- 
med before advanced scarring and immobility have occurred.

We thank John Newell for statistical guidance, Nancy Kriebel for preparing figures, and Drs James D Thomas, Christopher Y Choong, and John P O'Shea for advice.

GTW was supported in part by the Odlin Fellowship of the Royal Australasian College of Physicians, Wellington, New Zealand.

\section{References}

1 Lock JE, Khalilullah M, Shrivasta S, Bahl V, Keane JF. Percutaneous catheter commissurotomy in rheumatic mitral stenosis. N Engl J Med 1985;313:1515-8.

2 Palacios I, Lock JE, Keane JF, Block PC. Percutaneous transvenous balloon valvotomy in a patient with severe calcific mitral stenosis. J Am Coll Cardiol 1986;7:1416-9.

3 McKay RG, Lock JE, Keane JF, Safian RD, Aroesty JM, Grossman W. Percutaneous mitral valvotomy in an adult patient with calcific rheumatic mitral stenosis. J Am Coll Cardiol 1986;7:1410-5.

4 Al-Zaibag M, Ribeiro PA, Al-Kasab S, Al-Fagih MR. Percutaneous double balloon mitral valvotomy for rheumatic mitral valve stenosis. Lancet 1986;i: $757-61$.

5 Babic UU, Pejcic P, Djurisic Z, Vucinic M, Grujicic S. Percutaneous transarterial balloon valvuloplasty for mitral valve stenosis. Am J Cardiol 1986;57:1101-4.

6 Kveselis DA, Rocchini AP, Beekman R, et al. Balloon angioplasty for congenital and rheumatic mitral stenosis. Am J Cardiol 1986;57:348-50.

7 Palacios I, Block PC, Brandi S, et al. Percutaneous balloon valvotomy for patients with severe mitral stenosis. Circulation 1987;75:778-84.

8 McKay RG, Lock JE, Safian RD, et al. Balloon dilatation of mitral stenosis in adult patients: postmortem and percutaneous mitral valvuloplasty studies. J Am Coll Cardiol 1987;9:723-33.

9 Inoue $K$, Owaki T, Nakamura T, Kitamura F, Miyamoto N. Clinical application of transvenous mitral commissurotomy by a new balloon catheter. Thorac Cardiovasc Surg 1984;87:394-402.

10 Harken DE, Ellis LB, Ware PF, Norman LR. The surgical treatment of mitral stenosis. $N$ Engl J Me 1948;239:801-9.

11 Sellors TH, Bedford DE, Somerville W. Valvotomy i the treatment of mitral stenosis. Br Med J $1953 \overline{p^{2}}$ ii: $1059-67$.

12 Hoeksema TK, Wallace RB, Kirklin JW. Closed mitrâ commissurotomy; recent results in 291 cases. Am $\Phi$ Cardiol 1966;17:825-8.

13 Grantham RN, Daggett WM, Cosimi AB, et al. Transventricular mitral valvulotomy: analysis of factors influencing operative and late results. Circulation 1973;49(suppl II):203-11.

14 Ellis LB, Singh JB, Morales DD, Harken DE. Fiftee to twenty-year study of one thousand patients undergoing closed mitral valvuloplasty. Circulatioin 1973;48:357-64.

15 Morrow AG, Braunwald NS. Transventricular mitra commissurotomy. Surgery 1963;54:463-70.

16 Wann LS, Weyman AE, Feigenbaum H, et al. Deter mination of mitral valve area by cross-sectionap echocardiography. Ann Intern Med 1978;88:337-41. 음

17 Henry WL, Griffith JM, Michaelis LL, McIntosh CL Morrow AG, Epstein SE. Measurements of mitrat orifice area in patients with mitral valve disease bpo real-time, two-dimensional echocardiography. Cir: culation 1979;51:827-31.

18 Abbasi AS, Allen MW, DeCristofaro D, Ungaro Is Detection and estimation of the degree of mitraf regurgitation by ranged gated pulsed Dopple echocardiography. Circulation 1980;61:143-7.

19 Cohen MV, Gorlin R. Modified orifice equation for the calculation of mitral valve area. Am J Cardio $\bar{D}$ 1972;84:839-43.

20 BMDP statistical software. Department of Bio mathematics, University of California, Los Angeles?. Berkeley, California: University of California Press 1981.

21 Triulzi M, Gillam LD, Gentile F, Newell JB, Weyman AE. Normal adult cross-sectional echocardiographiভ values. Linear dimensions and chamber areas Echocardiography 1984;4:403-26. 